\title{
A biomimetic nanoparticle-enabled toxoid vaccine against melittin
}

This article was published in the following Dove Press journal:

International Journal of Nanomedicine

\author{
Tianyi Kang' \\ Chenyang $\mathrm{Li}^{1,2}$ \\ Ting Du' \\ Yujiao $\mathrm{Wu}^{\prime}$ \\ Yuping Yang' \\ Xuan Liu' \\ Qianqian Zhang' \\ Xiaoping $\mathrm{Xu}^{3}$ \\ Maling Gou ${ }^{1,4}$
}

'State Key Laboratory of Biotherapy and Cancer Center, West China

Hospital, Sichuan University, Chengdu 6I004I, People's Republic of China;

${ }^{2}$ Shanghai Institutes for Biological

Science, Chinese Academy of Science,

Shanghai 20003I, People's Republic

of China; ${ }^{3}$ West China School

of Pharmacy, Sichuan University,

Chengdu 6I004I, People's Republic

of China; ${ }^{4} \mathrm{Co}$-Innovation Center for

Micro/Nano Optoelectronic Materials

and Devices, Chongqing 402160,

People's Republic of China
Correspondence: Xiaoping Xu;

Maling Gou

West China Hospital, Sichuan

University, 17 People's South Road

Section 3, Chengdu, Sichuan, 6I004I,

People's Republic of China

Tel +86 I59 82896897 ;

+86 I3808640692

Email xul06@sina.com;

goumaling@scu.edu.cn
Background: Melittin, the main active peptide ingredient of bee venom, can cause severe cell membrane lysis due to its robust interaction with negatively charged phospholipids. So far, no effective anti-melittin vaccine has been developed to protect people from undesired melittin intoxication.

Methods: Herein, we prepared a polydiacetylene (PDA) nanoparticle with cell membrane-mimic surface to complex melittin, forming an anti-melittin vaccine (PDA-melittin).

Results: PDA nanoparticles could effectively combine with melittin and neutralize its toxicity. PDA-melittin nanocomplex is demonstrated to enhance melittin uptake by DCs and stimulate strong melittin-specific immunity. Mice immunized with PDA-melittin nanocomplex showed higher survival rate after exposion to melittin than untreated mice.

Conclusion: The PDA-melittin nanocomplex can efficiently and safely generate a specific immunity against melittin to protect body from melittin intoxication, providing a new method with potential clinical application for the treatment of melittin intoxication.

Keywords: PDA nanoparticles, melittin, toxoid vaccine, immunity

\section{Introduction}

Pore-forming toxins (PFTs) are membrane-damaging proteins secreted by bacteria and wild living creatures (e.g., snakes, scorpions and wasps). ${ }^{1,2}$ Melittin is an important PFT and the main active component of venom peptides. It can lyse cell membranes by inhibiting transport pumps, particularly $\mathrm{H}^{+} / \mathrm{K}^{+}$-ATPase and $\mathrm{Na}^{+} / \mathrm{K}^{+}$ATPase. ${ }^{3}$ This leads to significant morphological change and functional damage, especially in excitable tissues like nerves and glands. Additionally, the membrane disruption mechanism of melittin also depends strongly on the geometry of the lipid layer. Lateral phase separation and lipid heterogeneity play a crucial role in the membrane disrupting process of melittin. ${ }^{4}$ Melittin showed stronger spontaneous activity on heterogeneous raft-forming membranes compared with homogeneous non-raft forming membranes with the same amount of cholesterol, which provides a basis for the design of antimicrobial peptides.

Current strategies of treating toxoid intoxication basically rely on toxoid vaccine that processed with chemical or physical inactivation. ${ }^{5,6}$ Application of these strategies is restricted by the latent disruption of the epitope. ${ }^{7,8}$ Therefore, how to preserve the immunity epitope of melittin while eliminating its toxicity is a big challenge in the preparation of anti-melittin vaccines. In previous research on toxoid vaccine, erythrocyte membrane was separated to initiate nanoparticles which could entrap PFTs without compromising the structural integrity of toxins. ${ }^{9}$ The in vivo result shows that vaccination with nanoparticle-detained toxin stimulates stronger protective immunity against 
toxins compared with heat-denatured toxin vaccination. However, the potential immunogenicity risk is the greatest challenge when using exogenous erythrocyte membrane to form a toxin vaccine. Recently, researchers prepared a variety of multi-functional polymer nanoparticles with high affinity to toxin, reaching up to $100 \%$ neutralization efficiency. ${ }^{10}$ This research provided a new approach for designing advanced plasticity antidote. Based on our previous research, we found through computer simulation that nine conformations of negative binding affinities were obtained after docking polydiacetylene (PDA) nanoparticles to melittin. ${ }^{11}$ We concluded that PDA nanoparticles had the ability to interact with melittin through hydrophobic and electrostatic force, which further demonstrated that PDA nanoparticles could theoretically capture melittin. Since PDA nanoparticles are synthetic polymers without a non-immune prototype, they may overcome the risk of immunogenicity.

10,12-Pentacosadiynoic acid (PCDA) is the diacetylene monomer used for preparation of PDA nanoparticles. ${ }^{12,13}$ After ultraviolet irradiation, the diacetylene monomer will form ene-yne alternating polymer chains, which are responsible for the sensitivity of PDA nanoparticles to environmental changes, such as temperature variation, solvent changes, vapor exposure and $\mathrm{pH}$ variation, showing corresponding color change (blue to red) and emissive activation. ${ }^{14-16}$ The obtained PDA nanoparticles with specific vesicle structure are capable of sensing, attracting and neutralizing PFTs without causing protein denaturation, mimicking the role of normal cell membranes. ${ }^{17,18}$

In our study, we prepared a PDA-melittin complex to enhance immunity against melittin by incubation with PDA nanoparticles. PDA nanoparticles were characterized by size, zeta-potential, morphology, blood stability and toxin-binding efficiency. Furthermore, the antitoxin ability of the PDA-melittin complex vaccine against melittin was evaluated both in vitro and in vivo. We thus designed a biomimetic PDA nanoparticle based PFT antigen delivery platform. The platform consisted of analogous cell membrane mimic nanoparticles for the delivery of the perforation toxoid group, which could inspire the development of a broad-spectrum antitoxin vaccine and show potential application in PFT detoxification.

\section{Materials and methods Materials}

Melittin, 10, 12-pentacosadiynoic acid (PCDA), MTT reagent, bovine serum albumin (BSA), 4',6-diamidino-2phenylindole (DAPI) and coumarin were purchased from Sigma-Aldrich (St Louis, MO, USA). CD40-PE, Major
Histocompatibility Complex Class II (MHCII)-APC, CD80fluorescein isothiocyanate (FITC) and CD11c-PE antibodies (mouse) were purchased from Miltenyi Biotec (Bergisch Gladbach, Germany). Interleukin 4 (IL-4) and granulocytemacrophage colony stimulating factor (GM-CSF) were purchased from Bio-legend (San Diego, CA, USA). 3,3',5, 5'Tetramethylbenzidine (TMB) substrate was purchased from Beyotime Biotechnology (Shanghai, People's Republic of China). Goat anti-mouse $\operatorname{IgG}(\mathrm{H}+\mathrm{L})$, fetal bovine serum (FBS), Roswell Park Memorial Institute 1640 (RPMI-1640) and penicillin-streptomycin were purchased from Thermo Fisher Scientific (Waltham, MA, USA). All solvents used in this study were above analytical grade.

\section{Cell line and mice}

The 3 T3 fibroblast cell line was purchased from American Type Culture Collection (ATCC, Manassas, VA, USA) and cultured in RPMI-1640 medium with $10 \%$ fetal bovine serum, $100 \mathrm{U} / \mathrm{mL}$ penicillin, $100 \mu \mathrm{g} / \mathrm{mL}$ streptomycin, $400 \mu \mathrm{g} / \mathrm{mL}$ $\mathrm{G} 418$ and cultivated in an incubator at $37^{\circ} \mathrm{C}$ with $5 \% \mathrm{CO}_{2}$ atmosphere. All animals were purchased from Beijing HFK Bioscience (Beijing, People's Republic of China) and raised under pathogen-free conditions. Mice were habituated to the environment for at least two weeks before the experiment. Sixto eight-week-old female C57BL/6 mice were used to extract bone marrow cells and cultivate bone marrow derived dendritic cells (DCs). Six- to eight-week old female BALB/c mice were used to perform the immunoprophylaxis and immunotherapy studies of PDA-melittin against toxins. Mice were humanely treated according to the guidelines of the Institutional Animal Care and Treatment Committee of Sichuan University. All animal procedures were approved and controlled by the Institutional Animal Care and Treatment Committee of Sichuan University.

\section{Preparation of PDA nanoparticles}

To prepare polymerized nanoparticles, $12 \mathrm{mg}$ of PCDA was dissolved into dichloromethane and then filtered through a syringe filter (organic system; pore size $0.22 \mu \mathrm{m}$ ) (Millex-LG; EMD Millipore, Billerica, MA, USA) to purify the monomers before use. The filter liquor was put under rotary evaporation at $45^{\circ} \mathrm{C}$ for $30 \mathrm{~min}$ to remove the dichloromethane completely. Four $\mathrm{mL}$ double-distilled water at $60^{\circ} \mathrm{C}$ were added to re-dissolve the precipitate, followed by probe sonication for $15 \mathrm{~min}$ at $\sim 75^{\circ} \mathrm{C}$, then stored overnight at $4^{\circ} \mathrm{C}$. At last, the nanoparticles were crosslinked by irradiation with ultraviolet for $45 \mathrm{~min}$ at room temperature. The obtained solution was adjusted to $2 \mathrm{mg} / \mathrm{mL}$ with water and stored at $4{ }^{\circ} \mathrm{C}$. 


\section{Structural analysis of PDA nanoparticles}

Size distribution, average size and zeta potential were determined by Zetasizer Nano ZS (Malvern Instruments, Malvern, UK). The PDA nanoparticle solution was diluted to a suitable concentration, and the size and zeta potential of PDA nanoparticles were tested at $25^{\circ} \mathrm{C}$ after equilibration for $2 \mathrm{~min}$. The PDA nanoparticles were dyed with phosphotungstic acid and their morphology was examined by a transmission electron microscope (H-6009IV; Hitachi Ltd., Tokyo, Japan).

\section{Interaction between PDA nanoparticles and melittin}

Neutralization efficiency of PDA nanoparticles to melittin was measured by a red blood cell (RBC) lysis test. Fifty $\mu \mathrm{L}$ melittin $(10 \mu \mathrm{g} / \mathrm{mL})$ were pre-incubated with same volume of PDA nanoparticles (PBS as solvent). The PDA/ melittin mixture, free melittin $(5 \mu \mathrm{g} / \mathrm{mL}, 100 \mu \mathrm{L})$ and PBS were then incubated with $100 \mu \mathrm{L}$ murine $\mathrm{RBC}$ solution (4\%) for $30 \mathrm{~min}$ at $37^{\circ} \mathrm{C}$. Samples were then centrifuged at 2,000 rpm for $1 \mathrm{~min}$. Release of hemoglobin was monitored by measuring the absorbance $\left(\mathrm{A}_{\text {sample }}\right.$ ) of the supernatant at $540 \mathrm{~nm}$. Controls for 0 and $100 \%$ neutralization of hemolytic activity consisted of RBCs incubated with $5 \mu \mathrm{g} / \mathrm{mL}$ melittin $\left(\mathrm{A}_{0 \%}\right)$ and PBS $\left(\mathrm{A}_{100 \%}\right)$ respectively. The percentage of neutralization was calculated according to Equation 1:

$$
\begin{gathered}
\text { Neutralization } \\
\text { efficiency (\%) }
\end{gathered}=100-\frac{\mathrm{A}_{\text {sample }}-\mathrm{A}_{100 \%}}{\mathrm{~A}_{0 \%}-\mathrm{A}_{100 \%}} \times 100
$$

The intensity of red fluorescence emitted by the toxinbound PDA nanoparticles was measured over time. Then $100 \mu \mathrm{L}$ melittin $(0.1 \mathrm{mg} / \mathrm{mL})$ were added into $100 \mu \mathrm{L}$ PDA nanoparticles $(1 \mathrm{mg} / \mathrm{mL})$ (PBS as a solvent), and the red fluorescence intensity of the mixture was analyzed under a fluorescence microscope at different time points.

A drug release study was used to detect the release curve of melittin from PDA-melittin complex. Melittin was mixed with PDA nanoparticles at mass ratio of PDA:melittin=10:1 in deionized water. The mixture was then dialyzed in PBS using a dialysis bag (molecular cutoff weight is $80-120 \mathrm{kDa}$ ). Free melittin released from the PDA-melittin complex in the dialysate was collected at different time points, then the content was measured by high performance liquid chromatography (Zenix-C SEC-150, Sepax Technologies, Inc., Newark, DE, USA, $4.6 \times 300 \mathrm{~mm}$ column, $\mathrm{PBS}$ as liquid phase, $\mathrm{pH}=7.0$, flow rate $=1.0 \mathrm{~mL} / \mathrm{min}$, detection wavelength is $210 \mathrm{~nm}$ ). The one-point external standard method was applied to calculate the content of melittin according to Equation 2:

$$
\mathrm{C}_{\mathrm{x}}=\mathrm{C}_{\mathrm{r}} \times \frac{\mathrm{A}_{\mathrm{x}}}{\mathrm{A}_{\mathrm{r}}}
$$

where $\mathrm{C}_{\mathrm{x}}=$ sample concentration; $\mathrm{C}_{\mathrm{r}}=$ standard substance concentration; $A_{x}=$ peak area of sample; $A_{r}=$ peak area of standard substance.

The percentage of release was calculated according to Equation 3:

$$
\begin{aligned}
& \text { Release rate (\%) } \\
& =\frac{\mathrm{C}_{\mathrm{n}} \times\left[\mathrm{V}_{2}-(\mathrm{n}-1) \mathrm{V}_{1}\right]+\left(\mathrm{C}_{\mathrm{n}-1}+\ldots . .+\mathrm{C}_{2}+\mathrm{C}_{1}\right) \times \mathrm{V}_{1}}{\mathrm{n}} \times 100
\end{aligned}
$$

where $\mathrm{n}=$ time of sample collection; $\mathrm{c}=$ concentration of collected sample; $v=$ volume of collected sample.

\section{Generation of murine bone-marrow- derived DCs}

The bone marrow was obtained from female C57BL/6 mice aged 6 weeks. After repeated blowing of the cell suspension to disintegrate clusters, the RBC lysis buffer was added to remove RBCs from the suspension. After washing with RPMI-1640 medium twice, the cells were resuspended in RPMI-1640 medium containing GM-CSF $(10 \mathrm{ng} / \mathrm{mL})$ and IL-4 (10 ng/mL). After 48 -h cultivation at $37^{\circ} \mathrm{C}$ with $5 \%$ $\mathrm{CO}_{2}$ atmosphere, the cell supernatant was discarded and the precipitated cells were collected and resuspended with fresh medium, cultured in 6-well plates. The medium was totally replaced with fresh medium after $48 \mathrm{~h}$. Then half the medium was refreshed every 2 days with cytokines of appropriate concentration added. Six days later, all the suspended cells were collected to obtain rich bone marrow-derived DCs.

\section{In vitro cytotoxicity assay}

To evaluate the cytotoxicity of PDA-melittin complex, the cellular viability of DCs and murine $3 \mathrm{~T} 3$ cells were detected using an MTT assay. 3T3 cells and bone marrow derived DCs were planted in a 96 -well plate $\left(5 \times 10^{4}\right.$ cells $/$ well $)$ separately and then cultivated in an incubator overnight. When the cell density reached $60 \%, 100 \mu \mathrm{L}$ PDA-melittin complex solution ( $3 \mathrm{~T} 3$ cells, mass ratio PDA:melittin=10:1, the concentration of melittin is $6.25,12.5,25,50,100 \mu \mathrm{g} / \mathrm{mL}$, respectively; DCs, mass ratio PDA:melittin=10:1, the concentration of melittin is $12.5 \mu \mathrm{g} / \mathrm{mL}$ ) was added per well and incubated for $24 \mathrm{~h}$. Then $0.5 \%$ MTT was added, followed by incubation for $4 \mathrm{~h}$ under the same conditions. After removing the supernatant, $150 \mu \mathrm{L}$ DMSO was added into the well and then the plate was shaken at low speed on a shaker to dissolve the 
crystals completely. The OD value $(\lambda=570 \mathrm{~nm})$ of sample $\left(\mathrm{OD}_{\text {sample }}\right)$ and control $\left(\mathrm{OD}_{\text {blank }}\right)$ was detected and cellular viability was calculated according to Equation 4:

$$
\text { Cell viability }(\%)=\frac{\mathrm{OD}_{\text {sample }}-\mathrm{OD}_{\text {blank }}}{\mathrm{OD}_{\text {control }}-\mathrm{OD}_{\text {blank }}} \times 100
$$

\section{Cellular uptake of PDA-melittin complex to DCs in vivo and in vitro}

Cellular uptake of PDA-melittin complex in vitro could be evaluated by detecting the red fluorescence emitted from PDA-melittin nanocomplex in DC cytoplasm. For this, $500 \mu \mathrm{L}$ $(12.5 \mu \mathrm{g} / \mathrm{mL})$ melittin was incubated with the same volume of PDA nanoparticles (initial concentration is $125 \mu \mathrm{g} / \mathrm{mL}$ ) for $30 \mathrm{~min}$. Then the mixture $(1 \mathrm{~mL})$ was added to the DCs $\left(1 \times 10^{4}\right.$ cells/well) at $37^{\circ} \mathrm{C}$ with $5 \% \mathrm{CO}_{2}$ atmosphere for 1 $\mathrm{h}$. Then the cells were dyed with DAPI $(0.1 \mu \mathrm{g} / \mathrm{mL})$ and the cellular uptake of PDA-melittin complex was observed under a fluorescence microscope. Furthermore, the PDA nanoparticles which were labeled with coumarin were subcutaneously injected into mouse. After $24 \mathrm{~h}$, the draining lymph nodes at the injection site were taken out, completely ground and filtered to obtain a cell suspension. Then the obtained cells were marked with CD11c-PE antibodies and flow cytometry was used to test uptake efficiency of PDA nanoparticles by DCs in vivo.

\section{DCs maturation analysis}

DCs at day $6\left(3 \times 10^{5}\right.$ cells/well, 12-well plate $)$ were incubated with PDA-melittin complex loaded with $1.25 \mu \mathrm{g}$ melittin at $37^{\circ} \mathrm{C}$ for $24 \mathrm{~h}$ in incubator. Three surface antigen markers (PE-CD40, APC-MHCII and FITC-CD80) level was measured by flow cytometry (BD Biosciences, San Jose, CA, USA) and analyzed by FlowJo software Version 6 (TreeStar; Becton, Dickinson and Company, Franklin Lakes, NJ, USA).

\section{Immune protection analysis}

$\mathrm{BALB} / \mathrm{c}$ mice (6-8 weeks old, female) were immunized with PDA-melittin complex $(0.5 \mathrm{mg} / \mathrm{kg}$ melittin, PDA:melittin=10:1) every other week, three times in total $(n=10)$. Then the serum samples were collected at different time points. Enzyme linked immunosorbent assay (ELISA) was used to measure the IgG titers of anti-melittin specific antibodies. Then, a RBC lysis test was administrated to evaluate the neutralization rate of serum obtained from mice vaccinated after 28 days. The immunized mice received a lethal bolus dose of melittin at $3 \mathrm{mg} / \mathrm{kg}$ through intravenous tail-vein injection and the protective immunity against melittin was examined by the observation of survival rate over time.

\section{Results}

In this work, we developed a method of preparing PDA nanoparticles with appropriate size and uniform distribution. The formation process is presented in Figure 1A. We used the diacetylene monomer PCDA to self-assemble the spherical bilayer structure by probe sonication. The 1,4-photopolymerization activated by ultraviolet irradiation would form a $\pi$-conjugated backbone with alternating double- and triple-bond groups in the main polymer chain, which leads the polymer to have a deep blue color. ${ }^{11}$ The morphology analysis of the PDA nanoparticles was performed via transmission electron microscope. The size and zeta potential of PDA nanoparticles were also measured by Zetasizer Nano ZS. The equilibration time was $2 \mathrm{~min}$ and test temperature was $25^{\circ} \mathrm{C}$ during measurements. All results were expressed by the means of three test runs plus standard error. As shown in Figure 1B, the PDA nanoparticle prepared in our experiment presented a vesicle structure in the images of TEM and had an average diameter of about $70 \mathrm{~nm}$ (PDI=0.231) with a zeta potential of $-30 \mathrm{mV} \pm 1.2 \mathrm{mV}$ on its membrane (Figure 1D and E). The average diameter of PDA-melittin nanoparticle is $81 \mathrm{~nm}(\mathrm{PDI}=0.271)$ and the zeta potential is $-17 \mathrm{mV} \pm 0.8 \mathrm{mV}$ (Figure $1 \mathrm{~F}$ and $\mathrm{G}$ ). The absorption spectra of PDA nanoparticles containing a peak with a maximum at $650 \mathrm{~nm}$ could be observed (Figure 1C).

The interaction between PDA nanoparticles and melittin disrupts the extensively delocalized ene-yne backbones of molecularly ordered PDA side chains, thus causing a colorimetric response from this PDA material and inducing a fluorescence enhancement (Figure 2A). As shown in Figure 2B, binding melittin to PDA nanoparticles enhanced a red fluorescence and the fluorescence intensity gradually increased as the time of combination extended. As shown in Figure 2C, a higher concentration of melittin mixed with PDA nanoparticles could also lead to an increase of red fluorescence intensity. To evaluate the efficiency of PDA nanoparticles to neutralize melittin, we designed a RBC lysis test. In our test, the mixture of PDA and melittin was added into a $4 \%$ RBC solution. The melittin neutralization rates of PDA nanoparticles at different concentrations are shown in Figure 2D; observation of the supernatant can also indicate the neutralizing efficacy of PDA nanoparticles (Figure 2E). Based on these results, we concluded that the neutralization efficiency of PDA nanoparticles could reach up to $90 \%$ under the mass ratio of PDA:melittin $=10: 1$. 


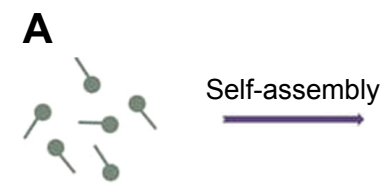

PCDA

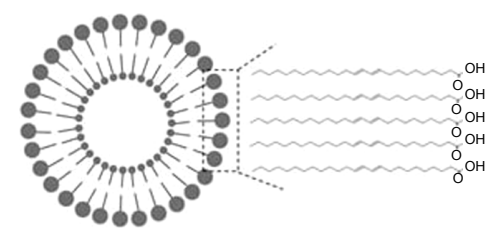

PCDA NP
UV irradiation

Polymerization

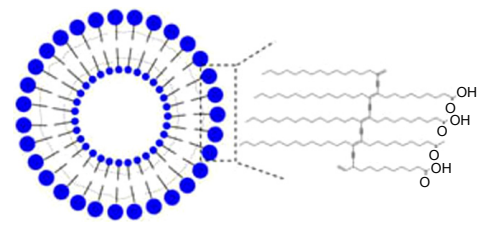

PDA NP
B
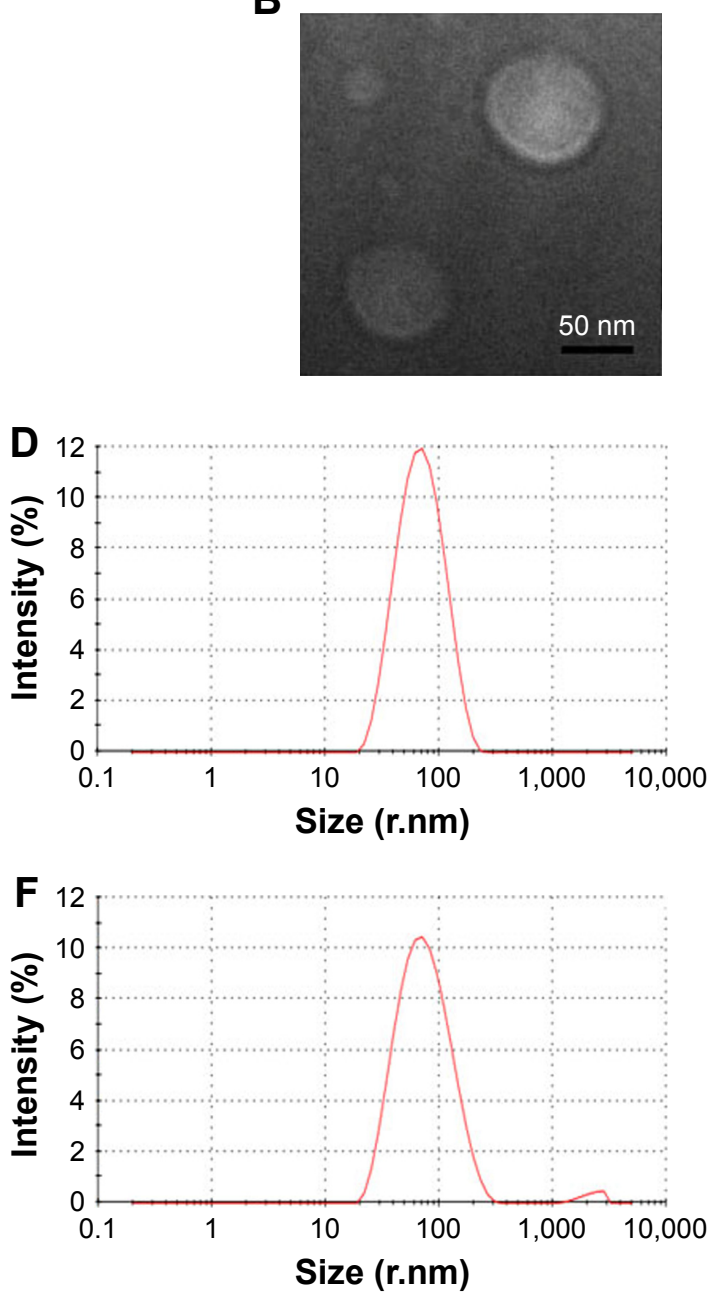

C
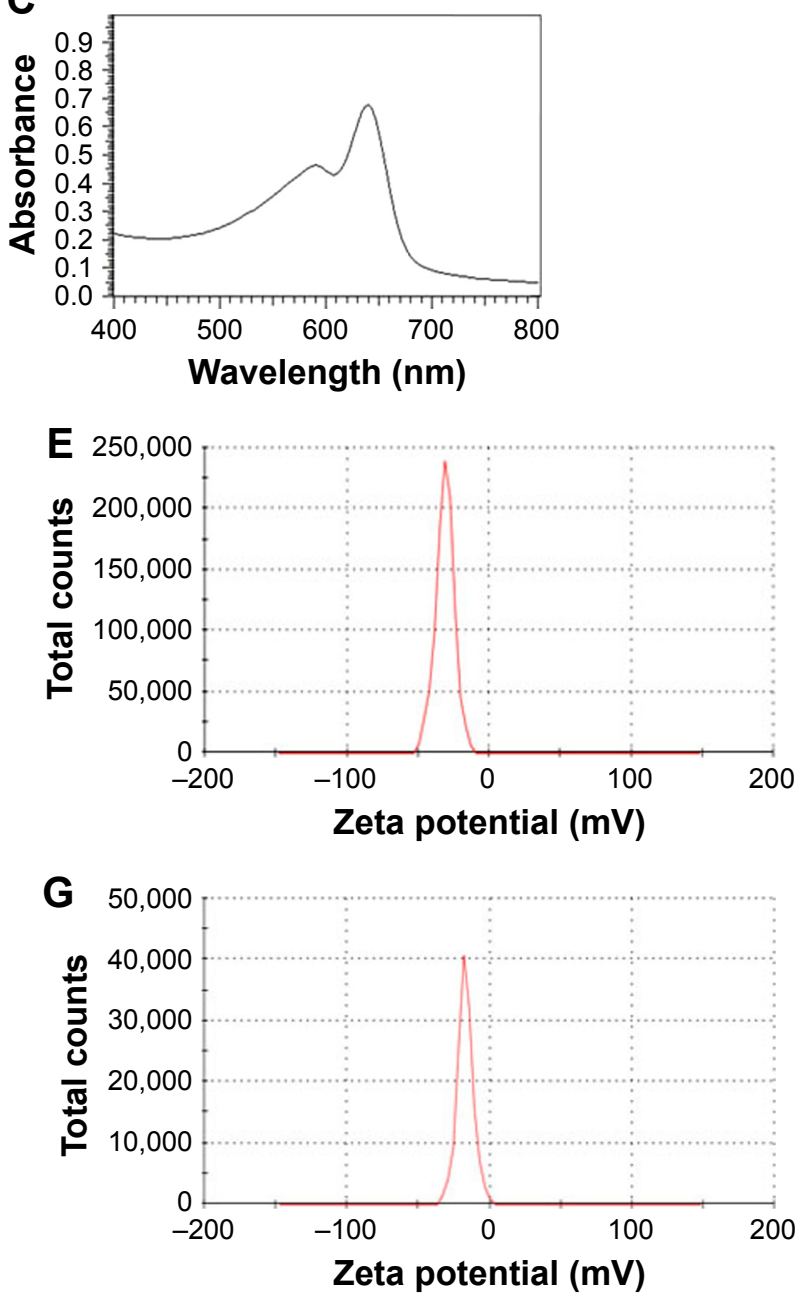

Figure I Characterization of PDA and PDA-melittin nanoparticles.

Notes: (A) A scheme of the self-assembly process of PDA nanoparticles with bilayer structure. PCDA was self-assembled into colorless nanoparticles after probe sonication at $70^{\circ} \mathrm{C}$. Polymerization of PCDA via a I,4-addition reaction was achieved by UV irradiation at $254 \mathrm{~nm}$, forming a blue polymer with alternating double-triple bond. (B) Transmission electron microscopy image of PDA nanoparticles. (C) UV spectrum of PDA nanoparticles. (D, E) The particle size distribution spectrum and the zeta potential distribution spectrum of PDA nanoparticles. $(\mathbf{F}, \mathbf{G})$ The particle size distribution spectrum and the zeta potential distribution spectrum of PDA-melittin nanoparticles. The test temperature was $25^{\circ} \mathrm{C}$. Abbreviations: PDA, polydiacetylene; PCDA, 10,12-pentacosadiynoic acid; NP, nanoparticle.

So we adopted this ratio and concentration as alternative criteria in our experiment. A drug release study demonstrated that melittin was firmly captured onto the PDA nanoparticles. We dialyzed the PDA-melittin complex or free melittin solution against phosphate-buffered saline (PBS) and collected the dialysate at eight time-points, using high performance liquid chromatography (HPLC) to determine the toxin release of both samples. As exhibited in Figure 2F, a fast growth phase of the release of toxin was observed within $1 \mathrm{~h}$, followed by a relatively stable phase. The free melittin sample released the toxin rapidly through the semipermeable membrane and the toxin release rate reached $100 \%$ in about $8 \mathrm{~h}$. However, the release rate of the PDA-melittin sample was under $20 \%$ within $24 \mathrm{~h}$, indicating that the combination between PDA nanoparticles and melittin is tight.

It is necessary to evaluate the toxicity of PDA-melittin complex for the application of toxoid vaccine. An MTT assay was used to evaluate the cytotoxicity of PDA-melittin 
A

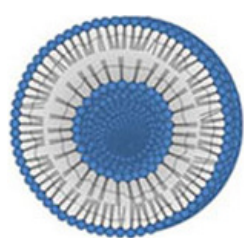

PDA
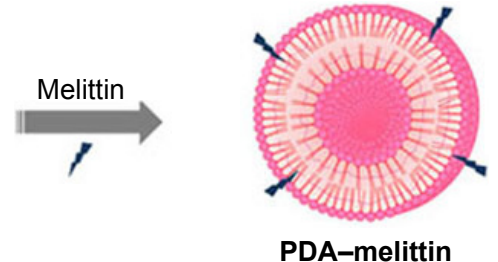

PDA-melittin
D

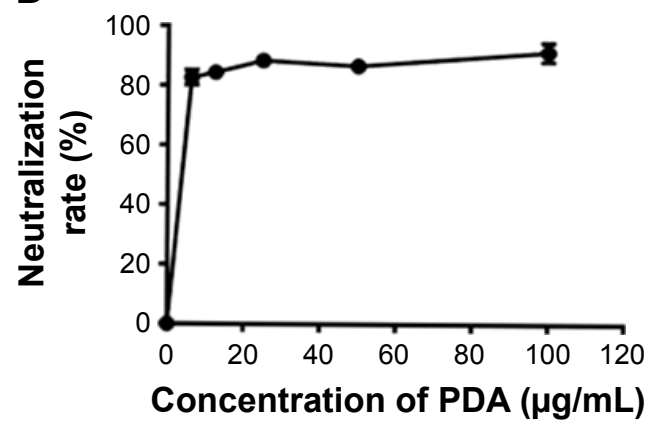

B

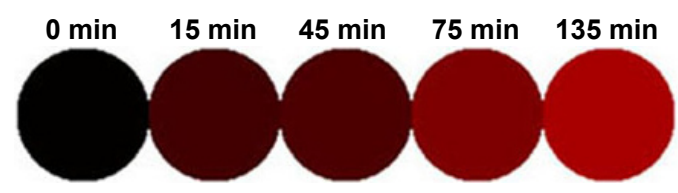

C

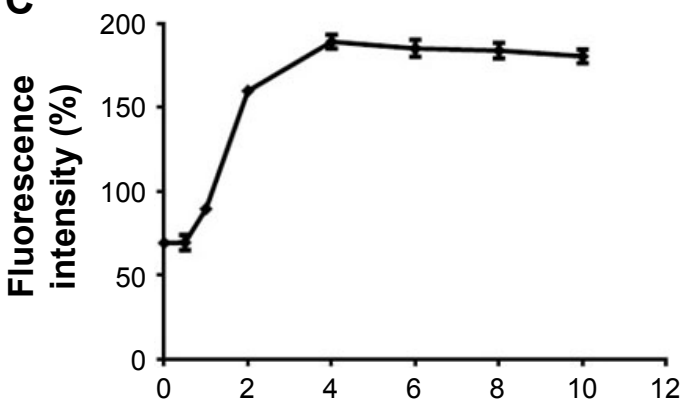

Concentration of melittin $(\mu \mathrm{g} / \mathrm{mL})$

E

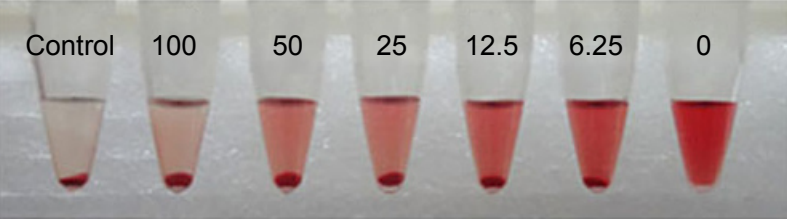

$\mathbf{F}$

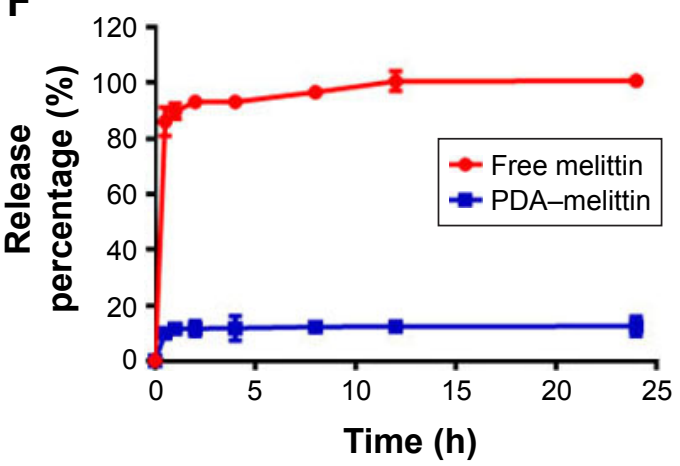

Figure 2 Interaction between PDA nanoparticles and melittin.

Notes: (A) Schematic presentation of the color variation after PDA binding with melittin. The solution color turns from blue to red after incubation at $37^{\circ} \mathrm{C}$ for 30 min. (B) The fluorescence alteration of PDA nanoparticles $(20 \mathrm{mg} / \mathrm{mL})$ after binding with melittin under a microscope at different time points. The fluorescence turned from none to red. (C) The red fluorescence intensity of PDA nanoparticles that were incubated with melittin of different concentrations at $37^{\circ} \mathrm{C}$ for 30 min. (D) The neutralization rate of PDA nanoparticles to melittin $(5 \mu \mathrm{g} / \mathrm{mL})$ at different ratios. (E) Centrifuged RBCs after incubated with melittin $(5 \mu \mathrm{g} / \mathrm{mL})$ combined with different concentrations of PDA nanoparticles. (F) Drug release of free melittin and PDA-melittin in vitro.

Abbreviations: PDA, polydiacetylene; RBCs, red blood cells.

complex to mouse $3 \mathrm{~T} 3$ fibroblast or DCs in vitro. As shown in Figure 3B, PDA could neutralize melittin (initial concentration is $12.5 \mu \mathrm{g} / \mathrm{mL}$ ) efficiently and the toxicity of PDA-melittin complex to normal cells was much weaker than free melittin. PDA-melittin complex showed up to $70 \%$ cellular viability of DCs, whereas free melittin caused 90\% cell apoptosis (Figure 3C), which implied a potential detoxification application in vivo.

The cellular uptake of nanoparticles by macrophages from the mononuclear phagocyte system indicated that the PDA nanoparticle could deliver melittin into antigenpresenting cells as a carrier. We incubated the PDA-melittin complex with DCs and then examined the cellular uptake of PDA nanoparticles by DCs under a fluorescence microscope. As shown in Figure 3A, the red fluorescence appeared in the cytoplasm of DCs, implying that DCs could completely uptake PDA-melittin complex in vitro. To prove that PDA nanoparticles could target DCs as a carrier in vivo, two groups of mice were subcutaneously injected with PBS (as a control) or PDA nanoparticles labeled by coumarin (green fluorescent). After $24 \mathrm{~h}$, the draining lymph nodes of the mice injection sites were obtained to extract DCs. DCs from the lymph nodes were marked with CD11c-PE antibodies and tested by flow cytometry. As shown in Figure $4 \mathrm{~A}$ and $\mathrm{B}$, much higher green fluorescence appeared in DCs from mice injected with PDA nanoparticles compared to the control, indicating that DCs could uptake PDA nanoparticles effectively. In addition, it was demonstrated that the PDA-melittin complex could target DCs efficiently. The mechanism of the PDA-melittin complex in promoting immunity against melittin was studied by detecting the specific cell surface antigen expression of DCs. The 
A
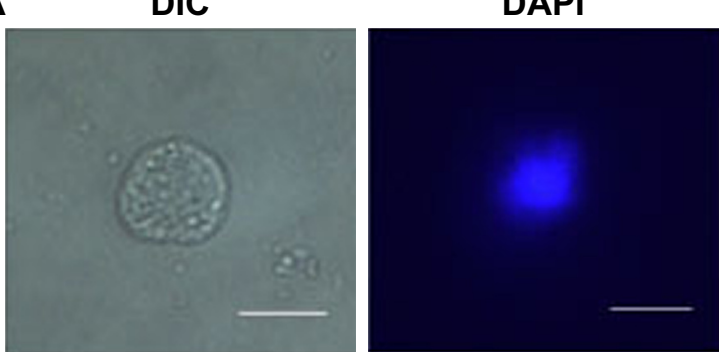

B

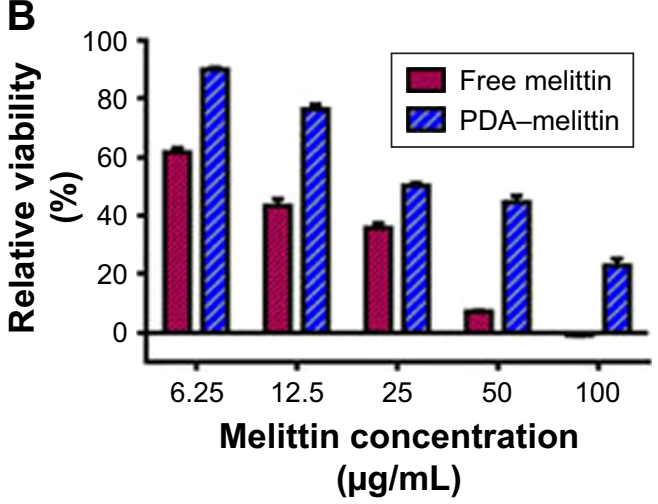

PDA-melittin

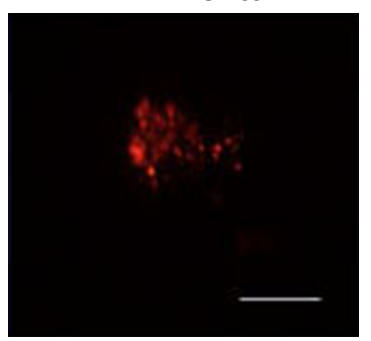

C

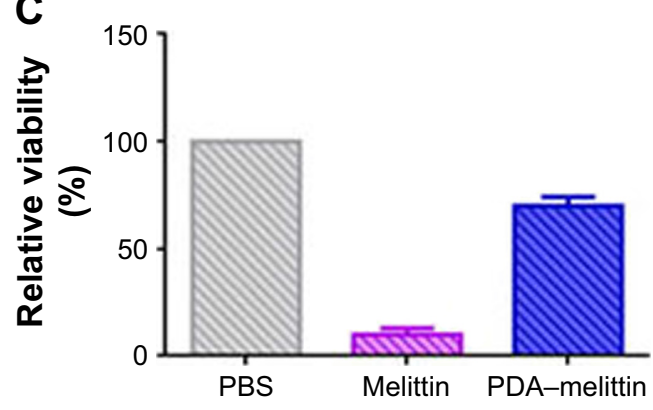

D
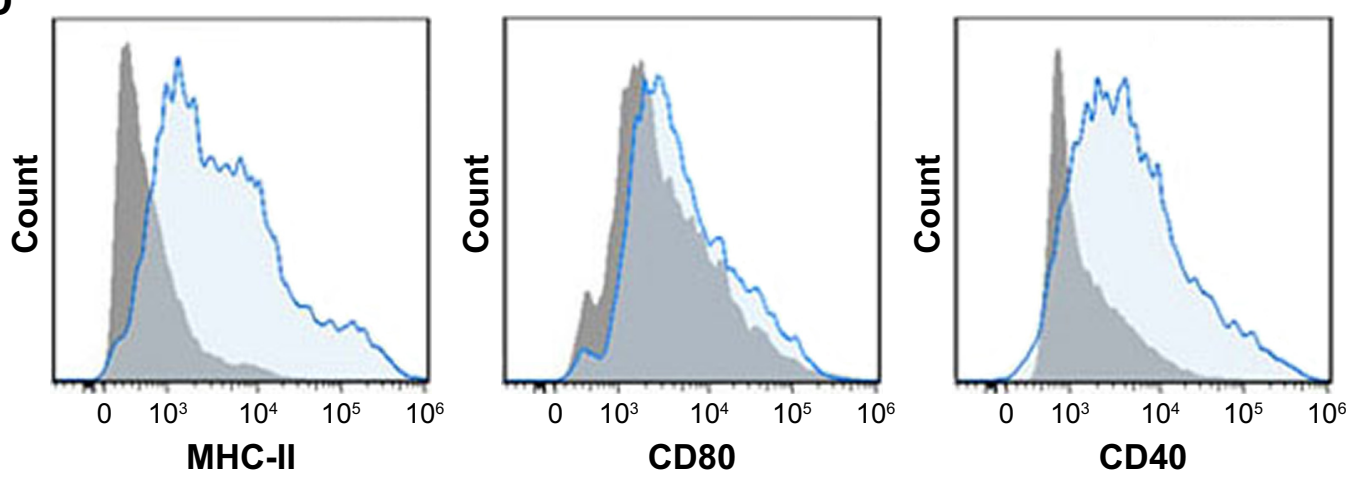

- Control - PDA-MLT

Figure 3 Characterization and immunization effect of PDA-melittin complex in vitro.

Notes: (A) Cellular uptake of PDA-melittin nanocomplex in DCs after incubation at $37^{\circ} \mathrm{C}$ with $5 \% \mathrm{CO}_{2}$ atmosphere for I h. Scale bar: $5 \mu \mathrm{m}$. (B) Cell viability of $3 T 3$ cells after treatment by PDA-melittin complex (PDA:melittin=10:I, the concentration of melittin is $6.25,12.5,25,50,100 \mu g / m L$, respectively). (C) Cell viability of DCs after treatment by PDA-melittin complex (PDA:melittin=10:I, the concentration of melittin is $12.5 \mu \mathrm{g} / \mathrm{mL}$ ). (D) The effect of PDA-melittin on the surface antigen expression of DCs. Abbreviations: DCs, dendritic cells; PDA, polydiacetylene; MLT, melittin.

MHCII, CD40 and CD80, which were closely related to DC maturation, were marked with fluorochrome-antibody and the expression level was detected by flow cytometry. As shown in Figure 3D, after a 24-h incubation of DCs and PDA-melittin complex in vitro, the DCs showed much higher fluorescence intensity in MHCII, CD40 and CD80 surface antigen than untreated DCs. This suggested that PDA-melittin complex could contribute to the maturation of DCs to achieve better effect of its antigen presentation, further enhancing immunity.

To further illustrate the immunity effect against toxin activated by PDA-melittin complex, we conducted a time-course study over 92 days and applied ELISA to examine the specific antibody titers of serum from mice. Mice were divided into three groups and immunized with PDA-melittin complex, heated melittin and free melittin respectively (3 immunizations, interval of each time is 7 days). As shown in Figure $4 \mathrm{C}$, the IgG titer level of PDA-melittin complex could reach the peak value $\left(3.2 \times 10^{4}\right)$ at day 28 after immunization, which was higher than those treated with heated melittin and free melittin. IgG titers of all groups reduced over time. The PDA-melittin complex group maintained a higher titer compared with the free melittin group, which gradually lost the protective immunity against melittin. The 
A

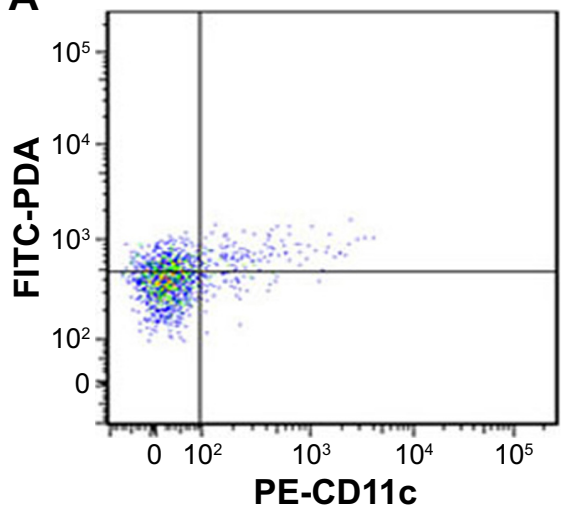

C

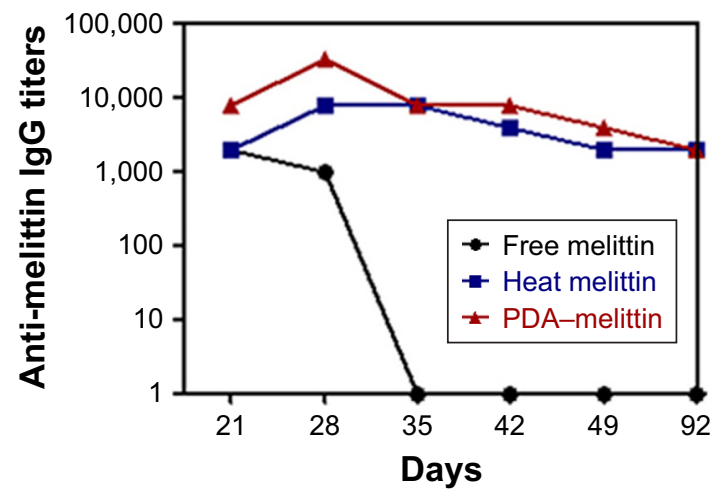

D

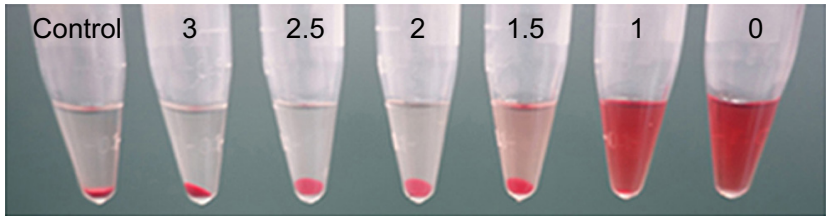

B

E
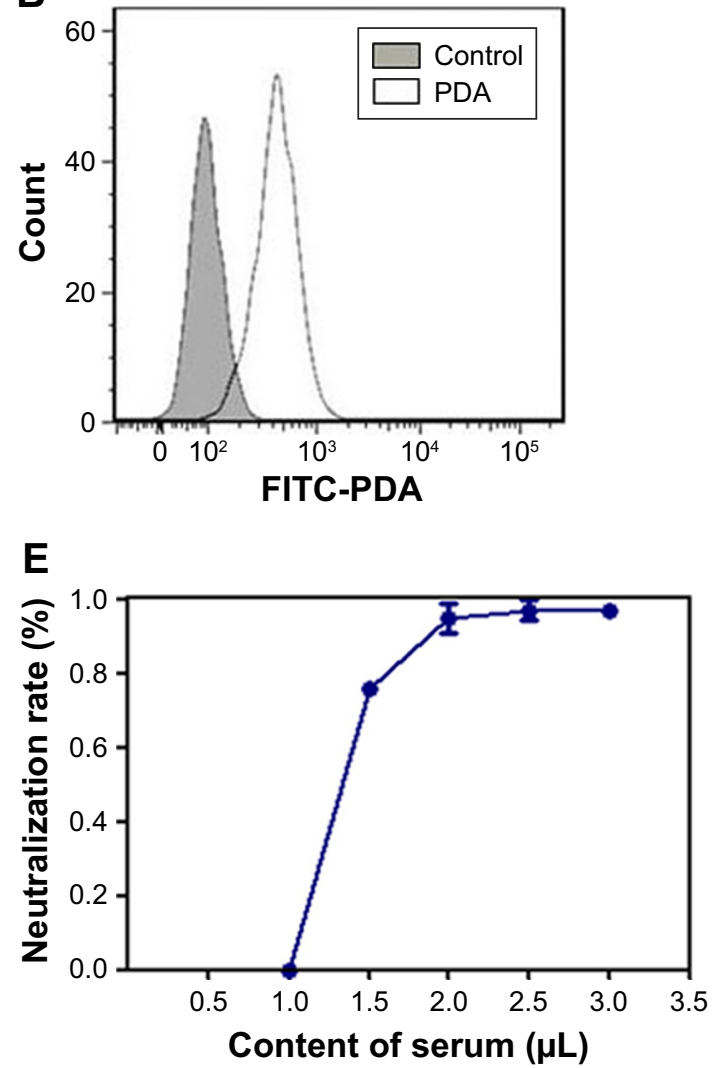

F

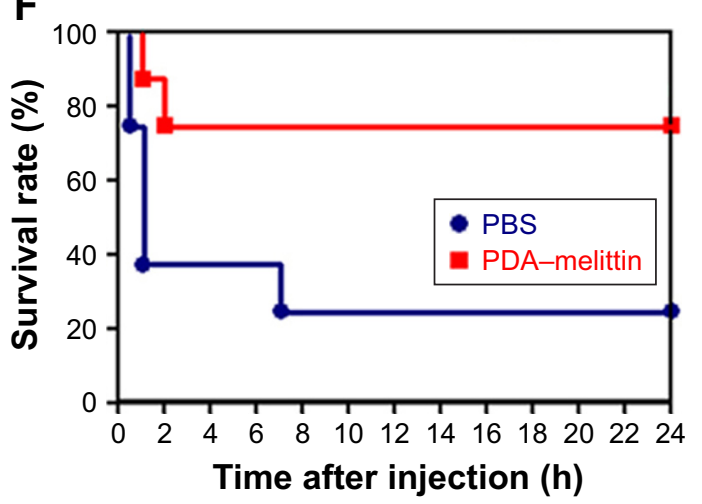

Figure 4 The immunization effect of PDA-melittin complex in vivo.

Notes: (A) The uptake of PDA nanoparticles to DCs in vivo by flow cytometry (scatter plot). (B) The uptake of PDA nanoparticles to DCs in vivo by flow cytometry (histogram). (C) Time course of anti-melittin IgG titers in free melittin treated mice (black circles), mice immunized with heat melittin (blue squares) or PDA-melittin complex (red triangles). (D) The hemolysis analysis of serum extracted from mice immunized with PDA-melittin complex. (E) The toxin neutralization effect of serum extracted from mice immunized with PDA-melittin complex. (F) Survival rate of mice challenged with melittin after immunized with PDA-melittin nanocomplex (red squares) and unimmunized (blue circles).

Abbreviations: PDA, polydiacetylene; FITC, fluorescein isothiocyanate; PE-CDI Ic, phycoerythrin-CDIIC.

efficient antigen delivering effect of PDA nanoparticles to the lymphatic system could cause higher specific antibody titers and improve immunological effect. Furthermore, we conducted a RBC lysis test to evaluate the neutralization rate of the serum obtained from mice vaccinated after 28 days. Melittin was mixed with the serum under different ratios and then incubated with murine RBCs for $30 \mathrm{~min}$. In Figure 4D and $\mathrm{E}$, we found that the hemolytic activity of melittin reduced with the increase of the serum. When the ratio of melittin:serum $=1: 2.5$ (melittin=1 $\mu \mathrm{g}$ ), the serum could completely neutralize the toxicity of melittin. This illustrated that the serum from the vaccinated mice contained anti-melittin substances which were able to produce effective resistance to melittin.

Finally, we examined the protective immune effect stimulated by PDA-melittin complex. At the fourth week, 
following 3 doses of vaccination, the mice received a toxin challenge of lethal bolus dose (melittin=3 mg $/ \mathrm{kg}$ ) through intravenous tail-vein injection. As shown in Figure 4F, the survival rate of the unvaccinated group decreased to $20 \%$ within $24 \mathrm{~h}$ after the injection of melittin, while $75 \%$ immunized mice survived under the same condition. The result showed that PDA-melittin vaccine could activate an effective immune prevention.

\section{Discussion}

Nanotoxoid strategy shows great promise in preparation of PFT vaccines. Compared with traditional chemical- and heat-mediated detoxification process, ${ }^{19-21}$ toxicity of PFTs is removed in a more moderate and effective way based on the interaction between PFTs and PDA nanoparticles. The PFTs captured by nanoparticles will be specifically and efficiently delivered to DCs. The preserved antigenic epitope on the toxin will effectively stimulate subsequent immunity. This method of antigen protection is supported by the existing application of biomimetic nanosponges in cargo delivery. ${ }^{22-24}$ Inspired by absorption of PDA nanoparticles to PFTs, we prepared PDA nanoparticles and demonstrated that the PDA-PFT complex is nontoxic and can induce antigenspecific protective immunity in vivo.

In previous research, we prepared PDA nanoparticles by ultraviolet irradiation of PCDA nanovesicles. ${ }^{11}$ PDA nanoparticles with vesicle structure and membrane-mimicking surface were used to attract, capture and neutralize melittin. The detoxification process is similar to that of the RBC membrane-coated nanoparticle system, which is reported before. ${ }^{9}$ However, compared with exogenous erythrocyte membranes, it is a reliable way to obtain an antidote without potential immunogenicity risks. Therefore, we explored the application of PDA nanoparticles in antitoxin vaccine in this research. The ene-yne alternating structure of the surface of PDA nanoparticles increases thermal stability and mechanical strength of the materials, indicating promising applications of the nanoparticles in bio-sensing. ${ }^{25-27}$ This is helpful to test the cellular internalization by DCs to PDA-PFT complexes. We incubated PDA nanoparticles with melittin, which is a model toxin, to evaluate the safety of a PDA-PFT complex by the RBC lysis test and drug release study. When we study the toxin releasing state in vitro, stimulus-responsive nanoparticles may be useful for constructing a biomimetic membrane model. As reported in previous research, ${ }^{28}$ hybrid liposomes formed by a photo-polymerizable lipid and saturated lipids go through a phase transition in a relevant temperature range, which provides possibilities for mimicking the varied conditions of the body microenvironment. Additionally, the uptake of PDA-melittin complex to DCs in vitro was observed under a fluorescence microscope. The uptake of DCs to PDA nanoparticles in vivo was tested by flow cytometry. All the results indicate that PDA nanoparticles might be safe and effective carriers to achieve toxoid vaccine delivery.

Based on the innate function of regulating immunity induction and tolerance maintenance, DCs are considered critical in underlying the body immune system. ${ }^{29-32}$ Both fluorescence tracking and flow cytometry test demonstrate the enhanced cellular uptake of PDA-melittin complex to DCs compared with the control groups. CD80 is the co-stimulus factor of CD86 in the process of T lymphocyte activation. Irritation of CD40 can upregulate the expression of MHCII, CD86 and CD80 on the cell surface of DCs and enhance the antigen-presenting effect of DCs effectively. ${ }^{33}$ In our study, the expression of CD80, CD40 and MHCII on the surface of DCs is increased after immunization by PDAmelittin complex, implying that PDA-melittin can promote DC maturation and enhance its antigen presenting. In the ELISA test, the ability of PDA-melittin complex to elicit specific antibody was evaluated. Meanwhile, PDA-melittin complex immunized mice had the capacity to survive after the challenge of a lethal bolus dose of melittin in vivo. No adjuvant was used in this study.

We conclude that PDA nanoparticle-mediated toxin antigen delivery could induce effective immune response and produce toxin-specific antibodies. Thus, PDA nanoparticlemediated toxin antigen delivery has promising applications in the preparation of broad-spectrum antitoxin vaccine. This strategy provides a theoretical basis and technical guide for achieving different kinds of PFT vaccines, such as $\alpha$-hemolysin (Hla- $\alpha$ ), and aerolysin. Since field work people are much easier to get to perforins, the practical application of these potential products is mainly in beekeeping, snake farming, military affairs, etc. People employed in these occupations could receive related toxin vaccines first for protection from unexpected detoxification.

\section{Acknowledgments}

This work was supported by the Sichuan Province Science and Technology Support Plan (2015SZ0049), the Foundation for Distinguished Young Scientists of Sichuan Province (2016JQ0020), the National Natural Science Foundation (81572990) and the National Key R\&D Program of China (2017YFA0104800). 


\section{Author contributions}

All authors contributed toward data analysis, drafting and critically revising the paper, gave final approval of the version to be published, and agree to be accountable for all aspects of the work.

\section{Disclosure}

The authors report no conflicts of interest in this work.

\section{References}

1. Dal Peraro M, van der Goot FG. Pore-forming toxins: ancient, but never really out of fashion. Nat Rev Microbiol. 2016;14:77-92.

2. Los FC, Randis TM, Aroian RV, Ratner AJ. Role of pore-forming toxins in bacterial infectious diseases. Microbiol Mol Biol Rev. 2013; 77:173-207

3. Alonzo F, Torres VJ. The bicomponent poreforming leucocidins of Staphylococcus aureus. Microbiol Mol Biol Rev. 2014;78:199-230.

4. Losada-Pérez P, Khorshid M, Hermans C, et al. Melittin disruption of raft and non-raft-forming biomimetic membranes: a study by quartz crystal microbalance with dissipation monitoring. Colloids Surf B Biointerfaces. 2014;123:938-944.

5. Greenberg RN, Marbury TC, Foglia G, Warny M. Phase I dose finding studies of an adjuvanted Clostridium difficile toxoid vaccine. Vaccine. 2012;30:2245-2249.

6. Gentschev I, Dietrich G, Goebel W. The E. coli alpha-hemolysin secretion system and its use in vaccine development. Trends Microbiol. 2002; 10:39-45.

7. Chen Z, Moayeri M, Zhao H, Crown D, Leppla SH, Purcell RH. Potent neutralization of anthrax edema toxin by a humanized monoclonal antibody that competes with calmodulin for edema factor binding. Proc Natl Acad Sci U S A. 2009;106:13487-13492.

8. Oyedeji OA, Fadero F, Joel-Medewase V, Elemile P, Oyedeji GA. Trends in neonatal and post-neonatal tetanus admissions at a Nigerian teaching hospital. J Infect Dev Ctries. 2012;6(12):847-853.

9. Hu CM, Fang RH, Luk BT, Zhang L. Nanoparticle-detained toxins for safe and effective vaccination. Nat Nanotechnol. 2013;8(12):933-938.

10. Hoshino Y, Urakami T, Kodama T, et al. Design of synthetic polymer nanoparticles that capture and neutralize a toxic peptide. Small. 2009; 5(13):1562-1568.

11. Gou M, Qu X, Zhu W, et al. Bio-inspired detoxification using 3D-printed hydrogel nanocomposites. Nat Commun. 2014;5:3774.

12. Yang JE, Park JS, Cho E, Jung S, Paik SR. Robust polydiacetylenebased colorimetric sensing material developed with amyloid fibrils of $\alpha$-synuclein. Langmuir. 2015;31(5):1802-1810.

13. Araghi HY, Paige MF. Deposition and photopolymerization of phaseseparated perfluorotetradecanoic acid-10, 12-pentacosadiynoic acid Langmuir-Blodgett monolayer films. Langmuir. 2011;27(17):10657-10665.

14. Zhang R, Su S, Hu K, Shao L, Deng X, Sheng W, Wu Y. Smart micelle@polydopamine core-shell nanoparticles for highly effective chemo-photothermal combination therapy. Nanoscale. 2015;7(46): 19722-19731.

15. Ho CC, Ding SJ. The $\mathrm{pH}$-controlled nanoparticles size of polydopamine for anti-cancer drug delivery. J Mater Sci Mater Med. 2013;24(10): 2381-2390.

16. Won SH, Sim SJ. Signal enhancement of a micro-arrayed polydiacetylene (PDA) biosensor using gold nanoparticles. Analyst. 2012;137(5): 1241-1246.
17. Xu F, Kang T, Deng J, et al. Functional nanoparticles activate a decellularized liver scaffold for blood detoxification. Small. 2016;12(15): 2067-2076.

18. Skočaj M, Bakrač B, Križaj I, Maček P, Anderluh G, Sepčić K. The sensing of membrane microdomains based on pore-forming toxins. Curr Med Chem. 2013;20(4):491-501.

19. Bierwisch A, Zengerle M, Thiermann H, Kubik S, Worek F. Detoxification of alkyl methylphosphonofluoridates by an oxime-substituted $\beta$-cyclodextrin - an in vitro structure-activity study. Toxicol Lett. 2014; 224(2):209-214.

20. Liu Y, Li J, Lu Y. Enzyme therapeutics for systemic detoxification. Adv Drug Deliv Rev. 2015;90:24-39.

21. du Rand EE, Smit S, Beukes M, Apostolides Z, Pirk CW, Nicolson SW. Detoxification mechanisms of honey bees (Apis mellifera) resulting in tolerance of dietary nicotine. Sci Rep. 2015;5:11779.

22. Hu CM, Fang RH, Copp J, Luk BT, Zhang L. A biomimetic nanosponge that absorbs pore-forming toxins. Nat Nanotechnol. 2013;8(5): 336-340.

23. Qu X, Gou M, Zaidan J, Zhang K, Chen S. Challenges and opportunities in developing nanoparticles for detoxification. Nanomedicine (Lond). 2014;9(16):2437-2439.

24. LeBrun EG, Diebold PJ, Orr MR, Gilbert LE. Widespread chemical detoxification of alkaloid venom by formicine ants. J Chem Ecol. 2015; 41(10):884-895.

25. Chen F, Xing Y, Wang Z, Zheng X, Zhang J, Cai K. Nanoscale polydopamine (PDA) meets $\pi$ - $\pi$ interactions: an interface-directed coassembly approach for mesoporous nanoparticles. Langmuir. 2016;32(46): 12119-12128

26. da Rocha Lindner G, Khalil NM, Mainardes RM. Resveratrol-loaded polymeric nanoparticles: validation of an HPLC-PDA method to determine the drug entrapment and evaluation of its antioxidant activity. Scientific WorldJournal. 2013;2013:506083.

27. Zhao Y, Zheng Y, Zhao C, You J, Qu F. Hollow PDA-Au nanoparticlesenabled signal amplification for sensitive nonenzymatic colorimetric immunodetection of carbohydrate antigen 125. Biosens Bioelectron. 2015;71:200-206

28. Kumar Pramanik S, Losada-Pe Rez P, Reekmans G, et al. Physicochemical characterizations of functional hybrid liposomal nanocarriers formed using photo-sensitive lipids. Sci Rep. 2017;7:46257.

29. Laresgoiti-Servitje E. A leading role for the immune system in the pathophysiology of preeclampsia. J Leukoc Biol. 2013;94(2): 247-257.

30. den Haan JM, Arens R, van Zelm MC. The activation of the adaptive immune system: cross-talk between antigen-presenting cells, T cells and B cells. Immunol Lett. 2014;162(2 Pt B):103-112.

31. Trabanelli S, Lecciso M, Salvestrini V, et al. PGE2-induced IDO1 inhibits the capacity of fully mature DCs to elicit an in vitro antileukemic immune response. J Immunol Res. 2015;2015:253191.

32. Kambayashi T, Laufer TM. Atypical MHC class II-expressing antigenpresenting cells: can anything replace a dendritic cell? Nat Rev Immunol. 2014;14(11):719-730

33. Jia J, Wang Z, Li X, Wang Z, Wang X. Morphological characteristics and co-stimulatory molecule (CD80, CD86, CD40) expression in tumor infiltrating dendritic cells in human endometrioid adenocarcinoma. Eur J Obstet Gynecol Reprod Biol. 2012;160(2): 223-227. 
International Journal of Nanomedicine

Dovepress

\section{Publish your work in this journal}

The International Journal of Nanomedicine is an international, peerreviewed journal focusing on the application of nanotechnology in diagnostics, therapeutics, and drug delivery systems throughou the biomedical field. This journal is indexed on PubMed Central, MedLine, CAS, SciSearch ${ }^{\circledR}$, Current Contents ${ }^{\circledR} /$ Clinical Medicine,
Journal Citation Reports/Science Edition, EMBase, Scopus and the Elsevier Bibliographic databases. The manuscript management system is completely online and includes a very quick and fair peer-review system, which is all easy to use. Visit http://www.dovepress.com/ testimonials.php to read real quotes from published authors.

Submit your manuscript here: http://www.dovepress.com/international-journal-of-nanomedicine-journal 